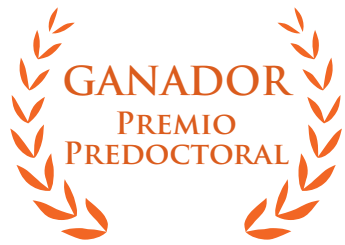

\title{
DiOMTS
}

Revista de Comunicación Digital

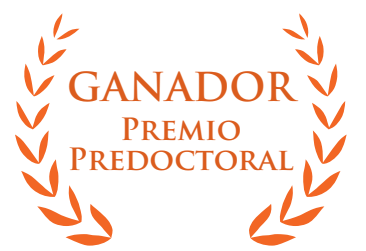

\section{La configuración del fenómeno ecologista \#FridaysForFuture como proceso de opinión pública digital en España}

\section{The configuration of the ecological phenomenon \#FridaysForFuture as a process of digital public opinion in Spain}

\author{
Rubén Rivas-de-Roca \\ rrivasderoca@us.es \\ Universidad de Sevilla (España)
}

\section{Resumen}

El cambio climático se ha erigido en los últimos tiempos en motivo de preocupación mediática y ciudadana, espoleado por una ola de protestas juveniles a lo largo del planeta. La estudiante y activista Greta Thunberg inició una serie de huelgas por el clima difundidas en Twitter bajo el hashtag \#FridaysForFuture, convirtiendo la Red en espacio de acción política, que se conectaba con la dimensión presencial.

Teniendo esto en cuenta, el presente estudio analiza la configuración del fenómeno \#FridaysForFuture como proceso de opinión pública digital en España. Para ello, se emplea la estrategia de investigación del estudio de casos, aplicados sobre tuits de interés para el desarrollo de este movimiento. Se busca obtener información sobre cinco grandes elementos: emergencia temática en redes, canales de expresión, dinámicas de interacción, interlocutores principales y análisis discursivo de sus mensajes.

Como resultados, se observan una serie de contenidos diseñados para jóvenes y dotados de fuerte carga emocional, cimentados en la idea de gobierno representativo. A pesar del carácter novedoso de la movilización, su objetivo es institucional, lo que se refleja en que sus interlocutores sean tradicionales, como los partidos políticos o los medios de comunicación. Estos últimos resultan clave para entender la aparición del fenómeno en España, ya que desde finales de 2018 informaban sobre la iniciativa de Greta Thunberg. Por tanto, en los mensajes recuperados de \#FridaysForFuture en España no se aprecia un origen tan participativo como en otros Estados, a lo que se suma un carácter menos individualista y más organizacional en Twitter frente al movimiento matriz.

\section{Palabras clave}

Cambio climático; movimiento estudiantil; opinión pública; Twitter; comunicación digital

Recibido: $13 / 10 / 2019$

Aceptado: 10/03/2020

Cómo citar este artículo:

Rivas-de-Roca, R. (2020). La configuración del fenómeno ecologista \#FridaysForFuture como proceso de opinión pública digital en España. Dígitos. Revista de Comunicación Digital, 6: 79-100. DOI: 10.7203/rd. v1i6.162 


\begin{abstract}
Climate change has gained more public opinion attention in recent years spurred by youth demonstrations around the world. The environmental activist Greta Thunberg started a wave of strikes under the hashtag \#FridaysForFuture on Twitter. This new movement uses the Internet as a place for making politics, combining these digital actions with traditional ones on the streets.

Bearing this in mind, the objective of this research is to delve into the shaping of \#FridaysForFuture as a process of digital public opinion in Spain. This paper uses the study of case research strategy in order to assess the first steps of the movement on Twitter. It is intended to get information on five categories: emergence as a topic on Twitter, strategies used by the movement, interaction triggered, main actors involved and discourse analysis of the messages.

The results show a range of tweets especially designed for young people's needs. Many of them rely on a strong emotional sense linking up the concept of representative government. Despite the novelty of the movement, the goal of \#FridaysForFuture is institutional. This is illustrated by the importance granted to traditional actors such as political parties or the media. In the case of Spain, media are key to understanding the emergence of the climate protests, as they reported on the initiative of Greta Thunberg since the end of 2018. Therefore, \#FridaysForFuture did not seem to have such a participative origin in Spain as in other countries. Besides, a less individualist and a more organizational performance on Twitter compared with the original movement is observed.
\end{abstract}

\title{
Keywords
}

Climate change; student movement; public opinion; Twitter; digital communication.

\section{Introducción}

En los últimos años ha aumentado la preocupación social por el cambio climático, convirtiéndose en un tema de debate público en numerosos países europeos. El Eurobarómetro de otoño de 2019 sitúa por primera vez esta cuestión como la principal preocupación de los ciudadanos de la Unión Europea, con un 32\% de los encuestados que la menciona como máxima prioridad (Comisión Europea, 2019). La degradación medioambiental y la escasez de recursos naturales llevan a una sensación de incertidumbre sobre el futuro del planeta, lo que se produce de forma paralela al desarrollo de las tecnologías digitales, que han revolucionado las prácticas comunicativas en el ámbito de la acción política (Gómez Isassi y Treviño Espinosa, 2015; Chadwick, 2017). En este contexto, surge en agosto de 2018 un movimiento social juvenil de carácter ecologista, bajo el hashtag \#FridaysForFuture, que logra alcance mundial, tras haber nacido como una huelga por el clima protagonizada por la adolescente sueca Greta Thunberg (Kühne, 2019)

La primera vez que el diario El País, el periódico generalista más vendido en España en la última década de acuerdo a la OJD (Oficina de Justificación de la Difusión, 2019), publicó una noticia sobre el movimiento \#FridaysForFuture fue el 4 de diciembre de ese año, en un breve texto sin firma centrado en la figura de Greta Thunberg. En España, el barómetro 
del CIS de mayo de 2018 muestra una preocupación residual de los ciudadanos por las cuestiones medioambientales, siendo mencionadas por un promedio situado en el 0,6\% de la población encuestada (Centro de Investigaciones Sociológicas, 2018). Esto puede haber provocado que la llegada del fenómeno \#FridaysForFuture se retrasara en España en comparación con otros países europeos, que en otoño de 2018 ya contaban con un movimiento asentado (Wahlström et al., 2019).

El perfil @JuventudxClima y las cuentas de la mayoría de organizaciones locales en torno a \#FridaysForFuture en España datan de febrero de 2019. En cualquier caso, el propio CIS (2018) recoge que el 67,9\% de los ciudadanos utiliza redes sociales. La integración de la población española con esta tecnología es, por tanto, alta, lo que abre la puerta a su empleo con fines de participación política entre los jóvenes, como ya había sucedido con el 15M (Fernández-Planells, Figueras-Maz y Feixa Pàmpols, 2014).

La presente investigación pretende analizar el fenómeno \#FridaysForFuture como un proceso relevante para la opinión pública, que nace y tiene lugar preeminentemente en Internet. El objetivo es estudiar los contenidos y dinámicas de este movimiento online en España, dado que la acción política cada vez se efectúa más en el plano digital (Cotarelo, 2010). Nuestro estudio se centra en la red social Twitter, que constituye la herramienta digital que más ha transformado la comunicación política (Campos-Domínguez, 2017; Alonso-Muñoz y Casero Ripollés, 2018). Twitter es una red social de microblogging que se adapta a la perfección a los rasgos de personalización, brevedad y aceleración de los flujos mediáticos propios del actual tiempo político, lo que explica su utilización en movimientos sociales recientes (Rubio Gil, 2013). A pesar de ello, en la conversación pública todavía desempeñan un papel importante los medios tradicionales (Luengo, 2014), generando un fenómeno de doble pantalla con el plano digital (Vaccari, Chadwick y O’ Loughlin, 2015).

La justificación de esta investigación radica en la trascendencia de \#FridaysForFuture, un fenómeno ecologista de éxito en lo referente a su difusión global, que logra convertir la cuestión climática en tema de interés para la opinión pública. La repercusión de este movimiento ha sido tal que su precursora -Greta Thunberg, una niña sueca de 15 años en ese momento- fue recibida por instituciones como Naciones Unidas y el Parlamento Europeo (Kühne, 2019). En España, esta iniciativa empezó a tener eco entre los jóvenes a principios de 2019, organizándose para el 15 de marzo de ese año actos reivindicativos en más de 40 ciudades españoles, en el marco de la huelga internacional de estudiantes por el clima (Wahlström et al., 2019).

\section{Opinión pública y participación política}

La opinión pública es un concepto poliédrico, construido históricamente en diferentes contextos culturales y que goza de máxima actualidad (Capellán, 2008). Los métodos de estudio de misma, cuantitativos o cualitativos, influyen en la delimitación de la idea de opinión pública. Frente a una visión simplificada que interpreta este concepto como una mera agregación de pareceres individuales, la opinión pública presenta un sustrato más discursivo, visible en dispositivos como las tecnologías digitales (Mañas Ramírez, 2013). Precisamente es en esos medios digitales donde prospera el fenómeno \#FridaysForFuture.

Autores como Capellán (2008) dividen la opinión pública en diferentes momentos según sus características. Tras un sentido científico de la opinión que domina las últimas décadas del siglo XIX y las primeras del XX, la situación más actual deriva del 
predominio de los medios de comunicación, que se articulan como armas en poder de grupos de intereses, impidiendo que el público desarrolle su propia valoración de temas relevantes. Se trata de un "momento mediático", que imbrica con la idea de "espectador teledigirido" de Sartori (1998).

Desde los años 90, los medios de comunicación adquieren una dimensión global, desempeñando un papel central en la sociedad (Capellán, 2008). La opinión pública de los individuos se ha suplantado por la perspectiva de los medios, determinados por condicionantes económicos y políticos (Bouza, 2004). Estos estudios se fundamentan en la influyente teoría de la agenda-setting (McCombs y Shaw, 1972), según la cual los temas de interés público vienen condicionados por la agenda temática de los medios.

Sin embargo, el auge de Internet, y en particular de las redes sociales, puede estar sustituyendo progresivamente el poder de los medios tradicionales, al menos como forma de participación política y expresión de la opinión pública (Chavero, 2013). La participación en asuntos públicos conlleva no solo acciones prácticas, sino también un elevado grado de compromiso político, que en el caso de los jóvenes varía de acuerdo a la tradición democrática de los países europeos (Kitanova, 2019). Una comunidad participativa políticamente es aquella en la que sus integrantes se implican en la toma de decisiones de actividades que les afectan (Dewey, 2004).

Los estudios consideran que los jóvenes son menos activos que el resto de la población en actividades como el ejercicio del voto (Blais et al., 2004; Gallego, 2009). En cambio, "la juventud ha sido pionera en la implantación social de unas herramientas y aplicaciones en la red sobre otras, y en concreto en la normalización del uso de las redes social en un breve lapso de varios años" (Rubio Gil, 2013: 283). Los nuevos movimientos juveniles han logrado organizarse con éxito gracias las herramientas digitales (Feixa, FernándezPlanells y Figueras, 2016), combinando elementos de participación clásicos con las redes sociales, algo que se experimentó en España con el 15M en 2011 (FernándezPlanells, Figueras-Maz y Feixa Pàmpols, 2014).

Si ampliamos el número de actividades que implica la participación política más allá del voto y la afiliación partidista, se observa cómo las redes sociales han resuelto las demandas de participación de la juventud, ya que se han insertado en el día a día de este colectivo gracias a su versatilidad técnica, con presencia en los móviles, así como debido a su posibilidad de contacto entre iguales y con personas distintas (Toret, 2013).

La literatura recoge la importancia de Internet, y en particular de Twitter, en el conocimiento y el desarrollo de iniciativas ciudadanas sobre el cambio climático (Newell y Dale, 2015; O'Brien, Selboe y Hayward, 2018). Esta red social no promueve un grado de intercambio significativo en el plano institucional (Alonso-Muñoz, Marcos-García y Casero Ripollés, 2017), pero sí que ha impulsado la participación política mediante este nuevo activismo digital sobre el clima (Kitanova, 2019).

\section{Antecedentes: \#FridaysForFuture como fenómeno global en Twitter}

El fenómeno \#FridaysForFuture tiene su origen en la huelga contra el cambio climático empezada el 20 de agosto de 2018 por la adolescente sueca Greta Thunberg (Kühne, 2019. Esta estudiante de secundaria comenzó a dejar de ir a clase los viernes durante la campaña electoral de las elecciones generales suecas para manifestarse ante el Parlamento de su país, con el objetivo de llamar la atención al futuro Gobierno sobre la necesidad de tomar medidas para hacer frente al cambio climático. Tras los comicios, 
celebrados el 9 de septiembre de 2018, Thunberg decidió seguir con su iniciativa, haciendo un llamamiento mundial el 16 de septiembre a través de Twitter para que los jóvenes de todo el mundo se sumaran a las huelgas mundiales por el clima.

Estas acciones por el clima pueden enmarcarse en la llamada "era del disentimiento", en la que los jóvenes hacen público su rechazo frontal a las prácticas económicas, sociales y medioambientales aplicadas hasta ahora por la clase política (O'Brien, Selboe y Hayward, 2018). Thunberg consiguió progresivamente que numerosos estudiantes de instituto de su país se unieran a la movilización. La originalidad de que un grupo de adolescentes suecos no asistiera a clase los viernes para denunciar el cambio climático fue objeto de atención de medios e instituciones internacionales, hasta el punto de que a Greta Thunberg se la invitó a participar en la Conferencia por el Clima de la ONU, celebrada en Polonia (COP24) en diciembre de 2018. Su intervención tuvo una difusión viral en la Red, abriendo las puertas a que el movimiento lograra dimensión mundial (Kühne, 2019).

Tras su participación en la COP24 y el alcance viral de su vídeo, las protestas por el clima se extendieron más allá de Suecia. Como recoge Almazán (2013), la comunicación horizontal instantánea que proporciona Internet quiebra las fronteras de los Estados, aumentado la visibilidad de pequeños movimientos, como fue en su nacimiento \#FridaysForFuture. Tanto en su origen como en su expansión, este fenómeno parece articularse de forma marcadamente personalizada. Su imagen global se traza en torno a la figura de Greta Thunberg. En Bélgica, primer país después de Suecia en el que se vivieron movilizaciones masivas, \#FridaysForFuture no se entiende sin la líder estudiantil Anuna De Weber, que difundió la primera convocatoria de huelga escolar a través de la Red (Wahlström et al., 2019).

La importancia de los liderazgos en este movimiento imbrica con el proceso de personalización de la política (McAllister, 2007), fruto primero de la televisión y en la actualidad fomentado por la proliferación de dispositivos digitales (Rodríguez-Virgili, Jandura y Rebolledo-de-la-Calle, 2014). Internet se ha convertido en el campo de juego de la acción política, institucionalizada o no, razón por la cual los actores protagonistas de \#FridaysForFuture han lanzado sus llamamientos a la huelga mediante redes sociales. Así ha sucedido también en España -país objeto de esta investigación-, donde un grupo de estudiantes universitarios de Girona instó en redes, desde enero de 2019, a que los jóvenes españoles se uniesen a las huelgas por el clima.

\#FridaysForFuture es un fenómeno que tiene mucho de comunicación sobre cuestiones políticas, para lo que resulta fundamental contar con una esfera pública, en la cual los ciudadanos actúan como depositarios de la democracia (Habermas, 1962), estructurada en este caso principalmente gracias a Internet. En el conjunto de la Red, Twitter es la herramienta digital que mejor se ha adaptado al campo de los asuntos políticos (Parmelee y Bichard, 2012). Su inmediatez o propensión a la viralidad hacen que el discurso político se adapte con facilidad a esta red social de microblogging.

Twitter constituye un medio consolidado de la comunicación política, siendo empleado por todo tipo de actores políticos, como partidos, gobiernos o la sociedad civil (CamposDomínguez, 2017). Desde 2009, políticos de todo el mundo han adoptado esta red social para involucrar a sus electores, convirtiéndola en un medio de comunicación más en elecciones (Chadwick, 2017). Su relevancia electoral no ha impedido que goce también de gran transcendencia para los movimientos sociales, que tienen un Twitter una herramienta tanto para la comunicación directa como para construir sentimiento 
de pertenencia (Toret, 2013).

A la vista de lo anterior, la investigación sobre esta red social y la política gira en torno a dos tendencias: el uso de Twitter por parte de los políticos y la utilización de la misma que efectúan los ciudadanos en el ámbito político (Bekafigo y McBride, 2013). Este último aspecto es el que nos interesa en este estudio, en tanto en cuanto \#FridaysForFuture se erige en un proceso de opinión pública protagonizado por jóvenes. A Twitter se le atribuye la capacidad de movilizar el voto, así como de aumentar la participación (Gainous y Wagner, 2014), elemento sumamente relevante para el análisis de la opinión pública.

La literatura sobre comunicación política en Twitter sostiene que este medio digital no fomenta una elevada fragmentación de la agenda (Segado-Boj, Díaz-Campo y Lloves, 2016; Alonso-Muñoz y Casero-Ripollés, 2018), es decir, que la mayoría de los temas tratados en este espacio han sido definidos por los líderes políticos. Sin embargo, existen investigaciones (Enli, 2017) que han demostrado la capacidad que las redes sociales tienen de construir agenda pública para aquellos actores que están fuera de ella, como los jóvenes y adolescentes que lideran las movilizaciones por el clima.

En cualquier caso, hay que tener en cuenta que en la popularización de iniciativas como \#FridaysForFuture contribuyen no solo las redes sociales, sino también los medios (Chavero, 2013). Los medios tradicionales permiten hacer llegar las protestas a ciudadanos alejados de los entornos digitales, a la vez que otorgan estatus a las movilizaciones. Además, su actividad periodística funciona como intermediaria de la comunicación ascendente y descendente entre el público de los ciudadanos y el sistema de la política (Bennett y Entman, 2001; Vaccari, Chadwick y O'Loughlin, 2015).

En lo referente a Twitter, su contenido solo se convertía inicialmente en noticia para hacer referencia a cuestiones de escaso peso político (Broersma y Graham, 2013), pero paulatinamente su uso se incrementó en las hard news (Justel-Vázquez et al., 2018). La movilización de los estudiantes por el clima supone uno de esos fenómenos digitales que acaba siendo objeto de coberturas periodísticas detalladas, aumentando el conocimiento político al respecto de manera distinta en función de las características de la audiencia (Ohme, 2019). Su capacidad de convocatoria, visible en varias huelgas globales, y su carácter novedoso en un ámbito hasta entonces caracterizado por la pasividad (Hopkel y Hestres, 2018), explican su repercusión mediática.

\section{Metodología}

El objetivo de esta investigación es conocer la configuración del fenómeno \#FridaysForFuture en España, en tanto que proceso relevante para la opinión pública que tiene un importante desarrollo en la red social Twitter. A partir de esta pretensión general se reconocen una serie de objetivos específicos:

O1. Estudiar la emergencia temática de este movimiento en Twitter.

O2. Evaluar los canales de expresión digitales en los que se articula \#FridaysForFuture.

O3. Analizar las dinámicas de interacción que llevan a cabo los actores implicados.

O4. Identificar a los interlocutores principales en Twitter de este movimiento en España. 
O5. Realizar un análisis discursivo sobre mensajes de gran repercusión difundidos en el seno de \#FridaysForFuture.

Partiendo de la revisión teórica efectuada, se establecen una serie preguntas de investigación para orientar el estudio descriptivo:

PI1. ¿Qué personalidades articulan el fenómeno \#FridaysForFuture en España?

PI2. ¿Qué estrategias comunicativas emplea este movimiento en Twitter en el caso español?

PI3. ¿Cuáles son los principales interlocutores de \#FridaysForFuture en Twitter?

Como se puede observar, las variables a estudiar son de tipo cualitativo, debido a que nos fundamentamos en una concepción de la opinión pública como fenómeno discursivo (Mañas Ramírez, 2013). El análisis de datos cualitativos supone un desafío para los investigadores, puesto que implica la sistematización de datos de diversa índole (Merlino, 2012). En este artículo, consideramos que explorar los contenidos y dinámicas característicos del formato online en la generación y expresión de \#FridaysForFuture como proceso de opinión pública requiere de un estudio cualitativo, prácticamente artesano, que desmenuce uno por uno los casos de interés. De esta forma se puede conocer mejor la articulación de este fenómeno, tal y como es objetivo de este trabajo.

Para lograr los objetivos propuestos y responder a las preguntas de investigación formuladas, esta investigación aboga por emplear la técnica del estudio de casos múltiples. Autores del área académica de comunicación (Gómez-Diago, 2010) sostienen que este tipo de herramientas, propias del ensayo, permiten conocer mejor las porosas realidades mediáticas actuales. El estudio de casos posibilita que los productos mediáticos analizados (tuits) sirvan como ejemplo significativo de la articulación de \#FridaysForFuture en España.

Por su parte, la etnografía virtual nos sirve como método de investigación, tratando al ciberespacio como una realidad etnográfica (Sádaba Rodríguez, 2012). Para su análisis se emplea una "observación flotante", a través de técnicas participantes sin presencia física, que aquí se dirigen al estudio de Twitter. Al suponer un objeto de estudio relativamente nuevo, son frecuentes las dudas sobre la fiabilidad de los resultados (Fielding, Lee y Blank, 2008). Lo más habitual es trasladar las técnicas clásicas de investigación a los espacios online (Jones, 1998), como propone esta investigación con el estudio de casos.

La recogida de la muestra se efectúa mediante la aplicación web Twitonomy. El corpus está formado por todos aquellos mensajes que emplean el hashtag \#FridaysForFuture en España durante cuatro meses (enero, febrero, marzo y abril de 2019), que coinciden con la emergencia del movimiento en el plano estatal. La muestra asciende a 1.933 mensajes, de los cuales se analizan en este trabajo 11 tuits valorados de gran interés para conocer la configuración del fenómeno, en los que el criterio de selección aplicado es su carácter pionero. Esto lleva a incluir los tuits iniciales del movimiento y los primeros que apostaron por estrategias comunicativas concretas (llamadas a la acción, exposición de datos científicos, etc.), así como las respuestas primigenias de actores políticos. Se incorpora también un tuit de Greta Thunberg que ilustra las formas de conexión global de la iniciativa.

Se ha aplicado el hashtag \#FridaysForFuture porque es el más conocido y singular de 
esta propuesta medioambiental, si bien también existen otros como \#Climatestrike, que hemos dejado de lado con el propósito de delimitar el trabajo de campo. Los hallazgos para el hashtag \#FridaysForFuture son presentados en los cinco grandes bloques definidos por la investigación:

-Emergencia temática en redes

-Canales de expresión

-Dinámicas de interacción

-Interlocutores principales

-Análisis discursivo

Con respecto al análisis del discurso, que supone el ámbito de investigación con mayor sustrato metodológico, se analizan cuatro elementos categorizados como clave en el discurso: orden y forma, sentido, estilo y retórica (Van Dijk, 2000). El estudio de esas materias resulta fundamental para describir y explicar las relaciones internas y externas de la forma de comunicación (Van Dijk, 1989), conformada aquí por tuits.

Detallando las categorías discursivas aplicadas, por orden y forma se estudia la distribución del texto, mientras que la variable "sentido" alude a una interpretación de su finalidad y "estilo" lo hace al grado de formalidad de los mensajes. Por su parte, la categoría de retórica sirve para analizar posibles figuras de este género que aparezcan en los tuits españoles sobre \#FridaysForFuture.

\section{Resultados}

\subsection{Aparición temática en Twitter}

El nacimiento del movimiento \#FridaysForFuture en Twitter puede fijarse en la cuenta de la adolescente sueca Greta Thunberg (@GretaThunberg), que inició su huelga estudiantil en agosto de 2018. El perfil de Thunberg, unida a Twitter poco antes -junio de 2018-, lanzó en septiembre un llamamiento global a la huelga por el clima (Wahlström et al., 2019). Fue la propia estudiante la que acuñó el hashtag \#FridaysForFuture, un lema de gran fuerza simbólica que dotó de identidad a la iniciativa, en una muestra de personalización de la política aplicada a los movimientos sociales (McAllister, 2007).

En España, las primeras noticias sobre el fenómeno estudiantil ecologista surgido en Suecia fueron publicadas por los medios de comunicación en diciembre de 2018. El 18 de enero de 2019, seis estudiantes de Girona, liderados por Lucas Barrero, protagonizan la primera huelga por el clima en este país, difundida a través del perfil de Barrero (@LuksBarrero), observándose de nuevo personalización y liderazgo en su puesta en marcha.

Barrero publica el tuit de inicio de la huelga en inglés, castellano y catalán, buscando alcanzar la máxima difusión posible. Como se puede comprobar, el inicio de la movilización es modesto, con solo seis personas, que se comprometen a concentrarse cada viernes ante la sede de la Generalitat de Catalunya en Girona para protestar contra la inacción política con el cambio climático. Sin embargo, el tuit de Barrero en inglés obtiene un elevado número de retuits (79) y favoritos (296), estimando que se trata de la cuenta de un particular desconocido hasta la fecha.

La propia Thunberg retuitea el mensaje del comienzo de la huelga en Girona, algo 
que suele hacer con las movilizaciones que se expanden a lo largo del globo, lo que contribuye a identificar a las distintas protestas con el movimiento de esta joven sueca. El nacimiento de la protesta en España tiene un carácter personalista mediante Lucas Barrero, tal y como sucede en otras partes de Europa y que encaja con una tendencia global a la personalización de la política en la Red (Rodríguez-Virgili, Jandura y Rebolledode-la-Calle, 2014). Sin embargo, pronto el caso español adquiere un cariz organizacional, con la aparición de asociaciones locales que estructuran la protesta en sus municipios. Estas entidades locales poseen cuentas propias en Twitter, la mayoría creadas en el mes de febrero. La pionera en España fue Fridays4Future Girona (@ForGirona), aparecida en enero de 2019.

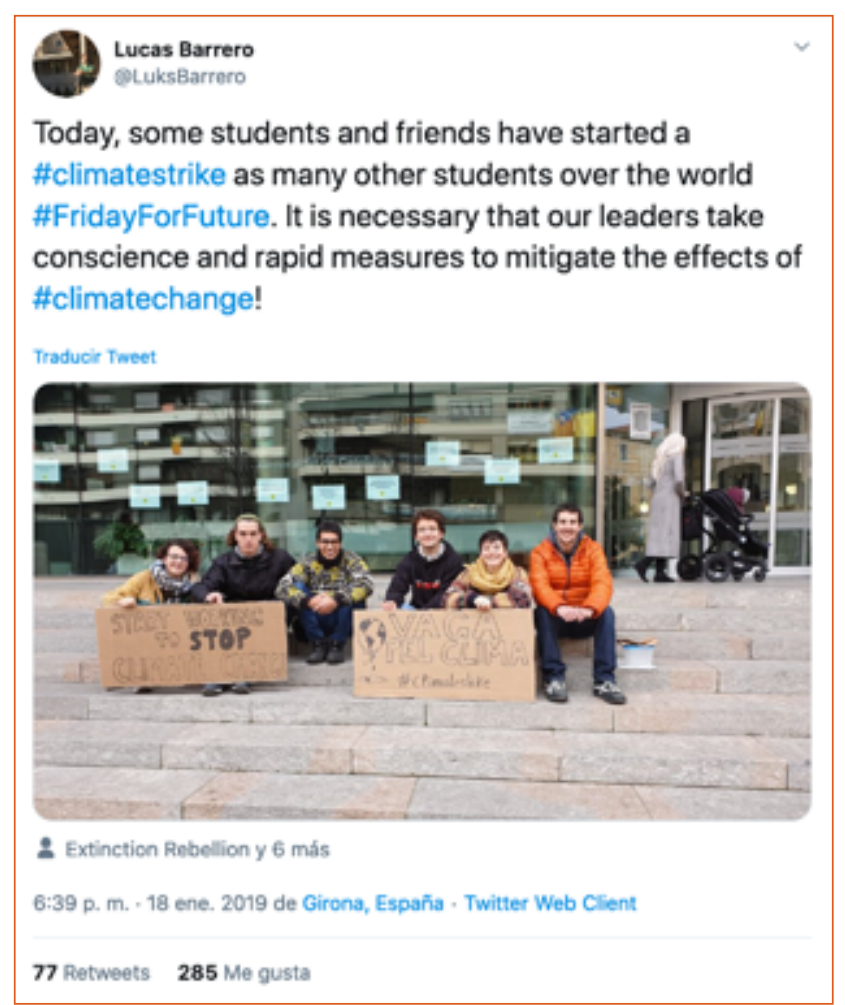

Imagen 1. Tuit de Barrero que recoge el inicio de la huelga climática en Girona.

Fuente: Twitter (@LuksBarrero).
Con la emergencia de las asociaciones locales van a ser sus perfiles de Twitter los encargados de dar difusión al movimiento. El 16 de febrero de 2019 Fridays4Future Girona comparte la primera noticia en prensa que se hace eco de las protestas en España, y en particular en Girona como primer foco. Esa información supone el pistoletazo de salida de una amplia cobertura en los medios, que contribuyen a la visibilidad de las protestas convocadas a través de la Red.

De manera paralela a la aparición de asociaciones presentes en Twitter en distintos puntos del territorio español, se crea una coordinadora estatal, bajo el nombre Juventud Por el Clima (@uventudXClima), que recoge las adhesiones al manifiesto de \#FridaysForFuture de Greta Thunberg en España. La cuenta @JuventudXClima se abre en febrero de 2019 y su primer mensaje es un retuit de la también recién creada Fridays For Future Barcelona, en la

que se convoca una protesta en la capital catalana que se une a la huelga mundial por el clima.

La rápida cobertura mediática, con la primera noticia sobre el caso español en febrero de 2019, deja entrever que existía una cierta predisposición a informar sobre el tema, puesto que \#FridaysForFuture era un movimiento de éxito a nivel global, con presencia en países de nuestro entorno. Esto hacía plausible que los jóvenes de España pudieran sumarse al manifiesto de Greta Thunberg. Los medios tardaron poco tiempo en dar cabida a este tema, pero su tratamiento puede estar ligado a picos de noticiabilidad. En cambio, de acuerdo a nuestra investigación \#FridaysForFuture en España sigue una serie de dinámicas en Twitter estables durante los cuatro meses estudiados.

\subsection{Canales de expresión}

La coordinadora que ha asumido la gestión del movimiento \#FridaysForFuture en España (Juventud Por el Clima) posee perfiles en Facebook, Twitter e Instagram. Sin embargo, es en Twitter donde tanto el estudiante pionero en este país como Fridays4Future 
Girona lanzaron sus primeras propuestas, convirtiéndose en la red social por excelencia de este fenómeno social. Una muestra de ello es el número de seguidores: Juventud Por el Clima posee más de 13.500 en Twitter, frente a 9.203 en Instagram y 5.054 en Facebook, según datos recabados a 20 de febrero de 2020. Este hecho motiva que Twitter constituya la red objeto de esta investigación. No obstante, Instagram también tiene importancia en este fenómeno, dado que Greta Thunberg comparte su huelga en esta herramienta, algo que también hacen muchas asociaciones \#FridaysForFuture locales españolas.

Analizando los mensajes en Twitter lanzados por el movimiento en España, se observa una tendencia a emplear tuits explicativos, que amplían su contenido a través de una imagen dotada de texto (Imagen 2). Esto resultó especialmente notable en el nacimiento del fenómeno en este país, cuando se publicaron estos mensajes como forma de contextualizar las causas y objetivos de la iniciativa. Muchos de estos tuits permanecieron fijados en las cronologías de los perfiles de Twitter pertenecientes al movimiento.

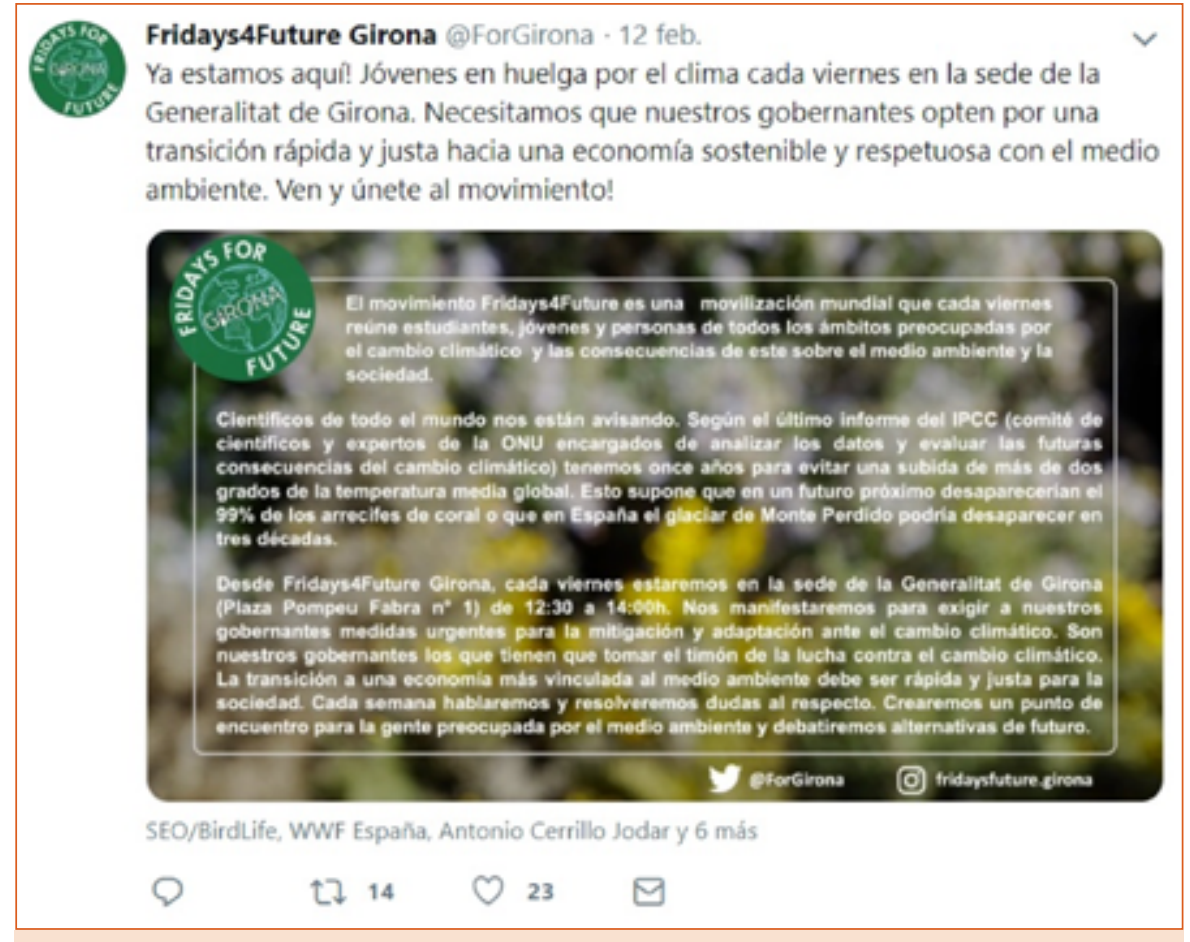

Imagen 2. Primer tuit de \#Fridays4Future Girona. | Fuente: Twitter (@ForGirona).
Como se puede observar, todo el planteamiento de \#FridaysForFuture, así como las acciones desarrolladas en una ciudad concreta, caben en un solo tuit. En el mensaje referenciado se expone que el movimiento tiene un objetivo institucional, pidiendo a los gobernantes que tomen medidas ante el cambio climático. No se trata, por tanto, de una protesta antisistema, sino de una reivindicación que promueve el cambio desde las propias instituciones, que son las consideradas como responsables para ello.

Twitter se erige en el canal de expresión habitual de \#FridaysForFuture en España, sirviendo como medio para difundir sus planteamientos y llamar a la huelga, lo que se efectúa principalmente por parte de las asociaciones locales constituidas. Además de tuits explicativos como el anteriormente citado, se publican mensajes dedicados exclusivamente a promover la protesta en la calle (ver Imagen 3). El movimiento recurre visualmente a la idea del planeta, presente desde su propio logo, pero también a la igualdad de sexos y a emoticonos que aluden al medioambiente, conceptos que enhebran con la movilización juvenil.

En el uso de Twitter llevado a cabo por el movimiento \#FridaysForFuture se aprecia asimismo una tendencia a recurrir a datos que evidencian la magnitud del problema cli- 
Juventud Por El Clima - Fridays For Future España. 18 abr. 2019

El próximo 25 de abril salimos a las calles de nuevo en todo el estado

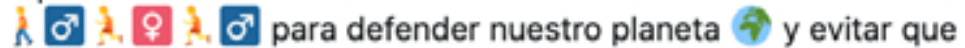
destruyan nuestro futuro $\nmid$ ¿Te unes a la lucha por el clima? \#FridaysForFuture

facebook.com/events/3895749...

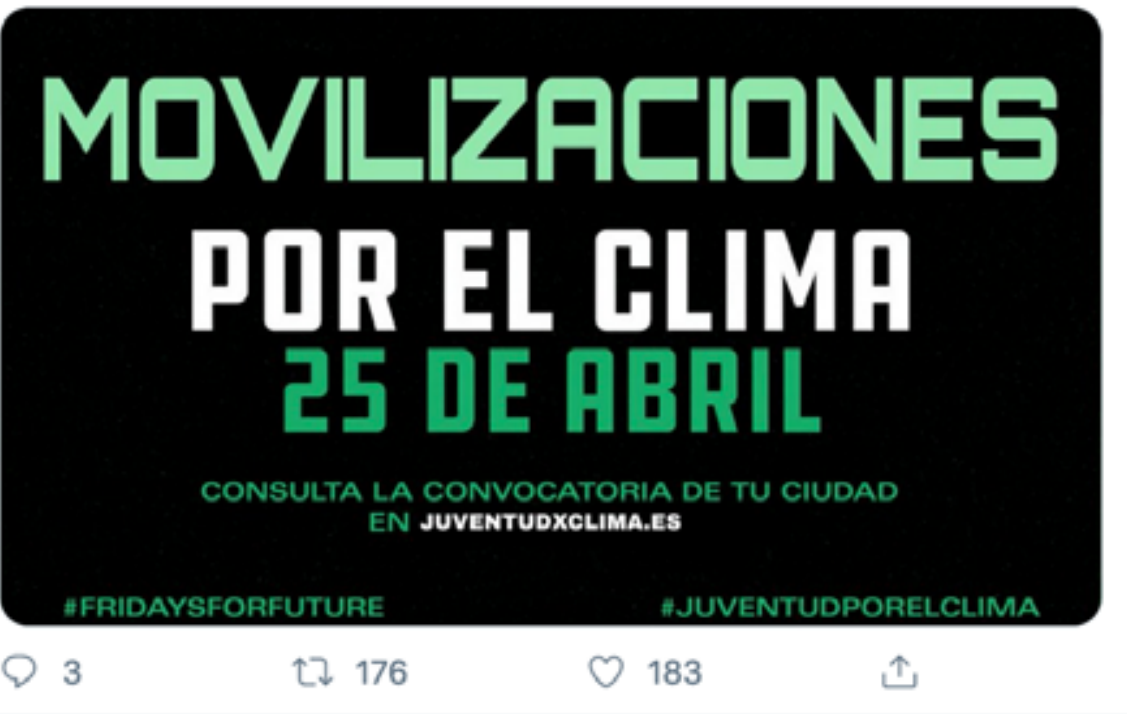

Imagen 3. Tuit llamando a la huelga publicado por Juventud Por El Clima. | Fuente: Twitter (@JuventudXClima). mático. El objetivo es que estas estadísticas se viralicen, propiciando la concienciación ciudadana sobre la necesidad de actuar ante el cambio climático. Siguiendo esta línea se efectúa un tuit (ver Imagen 4) de Fridays4Future Girona, que expone cifras acerca del crecimiento sostenido del dióxido de carbono en la atmósfera.

En suma, este movimiento juvenil ecologista se expresa de manera

visual, directa y pedagógica, empleando los tuits como canal de expresión. El tipo de lenguaje casa con las características de cercanía y contextualización localizadas por la literatura académica como propias para dar cuenta del cambio climático (Álvarez Martín, 2013). Se esquiva además la práctica recurrente de referenciar las cuestiones sobre clima como una problemática alejada, frente a lo que se apuesta por un estilo que remarca la conflictividad de la situación. Este uso del conflicto también es frecuente en la conversación en redes sociales sobre los problemas medioambientales (Anderson y

Huntington, 2017).

No hay duda de que el cambio climático y la propia concienciación sobre él se han desenvuelto de forma paralela al crecimiento de las tecnologías digitales. Si bien el movimiento \#FridaysForFuture nace en la Red, desde un primer momento trasciende al espacio público físico, ya que Twitter sirve como plataforma para reivindicar y anunciar las movilizaciones en la calle. El proceso de opinión pública producido en esta red social aúna el plano digital y el de la acción presencial.

Las protestas se concentran ante las sedes de las administraciones públicas de mayor rango en cada ciudad. Desde los inicios con la huelga de Thunberg en Suecia, el

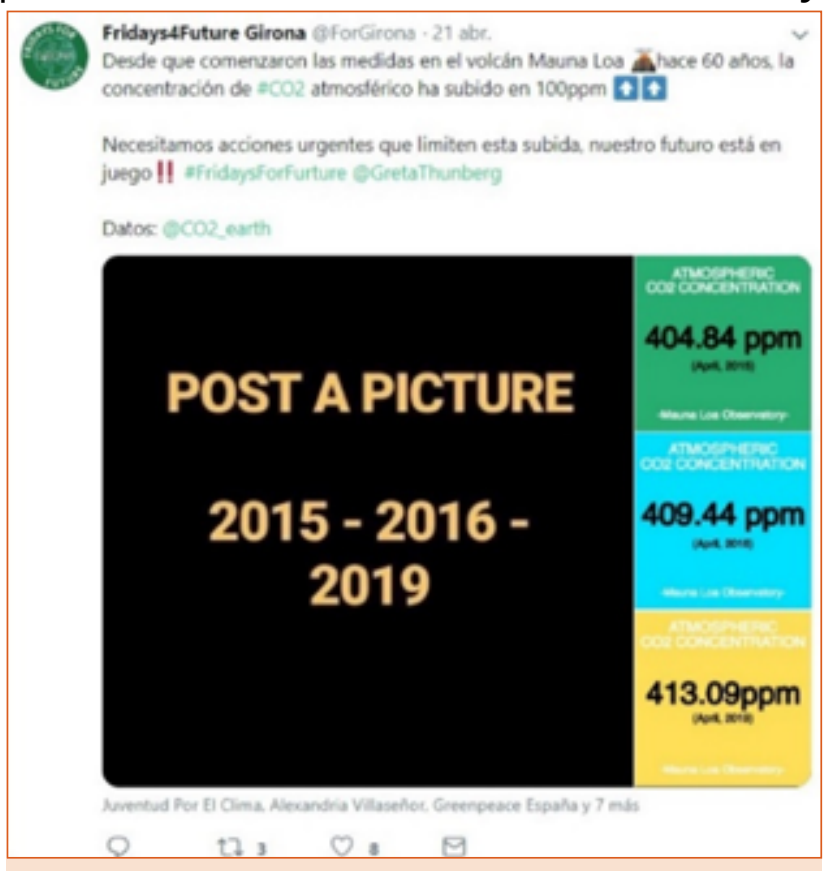

Imagen 4. Tuit de Fridays4Future Girona sobre la concentración de $\mathrm{CO} 2$ atmosférico. Fuente: Twitter (ForGirona). 
movimiento considera importante la presencia en las calles y plazas, lo que denota un reconocimiento de este canal como vía de llegar a la ciudadanía. De hecho, muchos de los tuits publicados en torno a \#FridaysForFuture se encargan de recabar y publicitar las actuaciones efectuadas en la calle.

\subsection{Dinámicas de interacción}

Los tuits iniciales de \#FridaysForFuture en España trataron de promover la interacción con los más importantes actores ecologistas del país, en aras de lograr su adhesión $\mathrm{y}$, con ello, impulsar un movimiento que en sus primeras protestas no alcanzaba la decena de personas. Una de las técnicas empleadas pasa por etiquetar en los tuits a los perfiles de interés en la materia. Por ejemplo, en el primer tuit de Fridays4Future Girona -la primera asociación local constituida- se etiquetó a las entidades ecologistas SEO/BirdLife, WWF España y Ecologistas en Acción, a los periodistas especializados en medioambiente Antonio Cerrillo Jódar (La Vanguardia) y Manuel Planelles (El País), el meteorólogo Tomàs Molina, las activistas Alexandra Villaseñor y Asun Ruiz, y el Ministerio de Transición Ecológica.

En ese primer tuit de Fridays4Future Girona analizado se aprecia una voluntad por comunicar el movimiento a los grupos ecologistas, pero a su vez por llegar a los ámbitos mediático e institucional. También sucede de esta manera en el tuit aludido en la Imagen 3, el primero que llama a la huelga del 25 de abril. En él se etiqueta a la agencia EFE (a través de su delegación para medioambiente EFEVerde), las organizaciones Ecologistas en Acción, Greenpeace España, SEO/BirdLife, Amigos de la Tierra y Extinction Rebellion Spain, así como a Teresa Ribera, Ministra para Transición Ecológica.

Greta Thunberg 0

QretaThunberg

March 15.

The school strike continues.

957 places in 82 countries and counting...

Everyone is needed.

Everyone is welcome.

Please spread the word!

Find your closest strike or register your own at

fridaysforfuture.org/events/list

\#FridaysForFuture \#SchoolsStrike4Climate

\#ClimateStrike

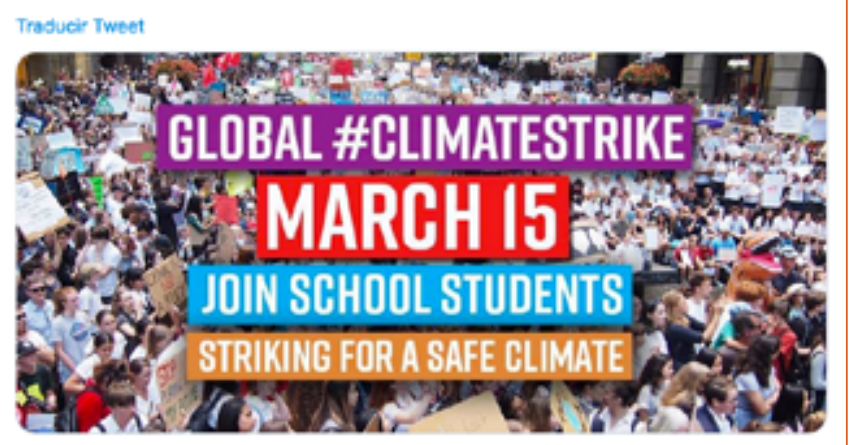

1:39 p. m. - 10 mar, 2019 - Twitter for iPhone

5,2 mil Retweets 9 mil Me gusta

Imagen 5. Tuit de Thunberg con las posibles vías de participación.

Fuente: Twitter (@GretaThunberg).
Los tuits analizados cuentan con una baja tasa de respuestas, por lo que no se produce una interacción con la ciudadanía más allá de los retuits y favoritos. No obstante, el movimiento trata de facilitar la interacción entre activistas, ya que permite localizar la protesta más cercana o registrar una nueva a través de una página web que Thunberg comparte con frecuencia (ver Imagen 5).

Otros actores en la lucha contra el cambio climático, como Extinction Rebellion -movimiento global frente a la crisis ecológica surgido en Londres- o Madres por el Clima, retuitean los contenidos de \#FridaysForFuture, a la vez que son citados en la cuenta de la coordinadora estatal @JuventudXClima. La interacción entre estos perfiles medida en menciones recíprocas es máxima, mostrando como el planteamiento de \#FridaysForFuture impulsa en la primavera de 2019 protestas en respuesta al cambio climático desde sectores más amplios de la sociedad. En cualquier caso, hay que 
tener en cuenta que el citado movimiento Extinction Rebellion comporta una acción más radical, al introducir el bloqueo a los servicios públicos (Shah, 2019), lo que trasciende de la mera huelga educativa promovida por \#FridaysForFuture.

Por otro lado, existen partidos políticos en España que han apoyado públicamente el movimiento, como PSOE, Podemos, Izquierda Unida y Equo. De todos ellos, Podemos es el que interactúa más claramente con los contenidos digitales publicados por las cuentas de \#FridaysForFuture. Como se observa en la Imagen 6, el perfil nacional de Podemos retuitea con comentarios un mensaje de Fridays For Future Madrid, aportando información propia al contenido que apoyan con su retuit.

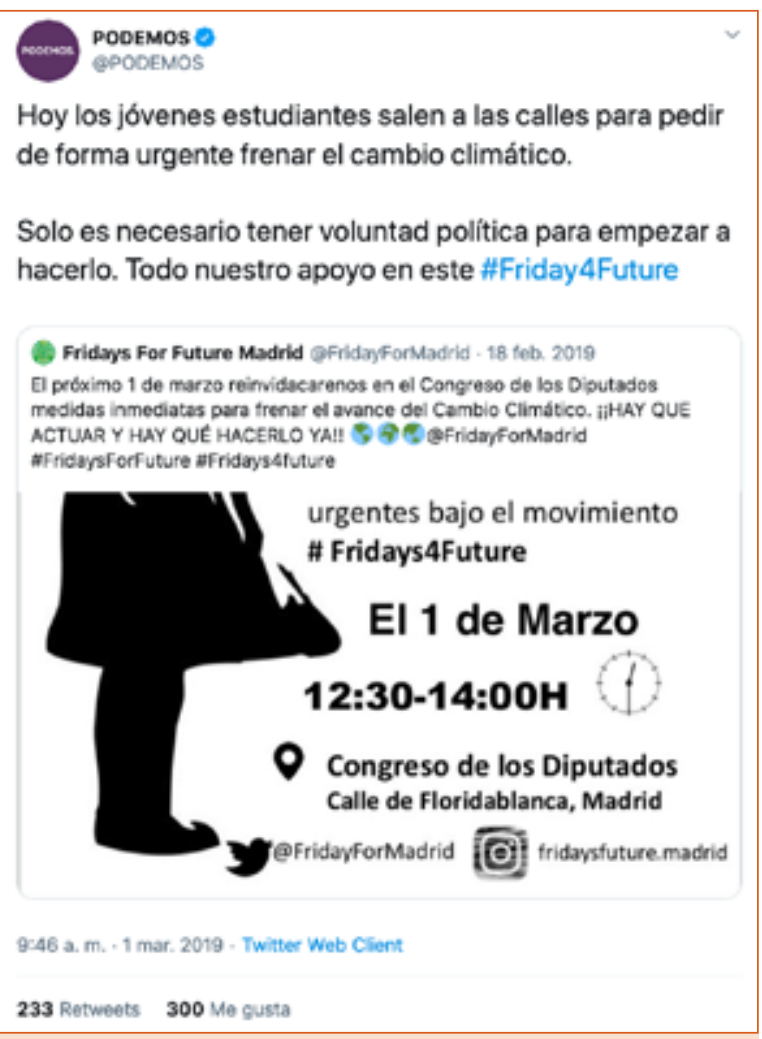

Imagen 6. Retuit con comentario de Podemos apoyando \#FridaysForFuture. Fuente: Twitter (@ahorapodemos).

\subsection{Interlocutores principales}

La cuenta @JuventudXClima, los perfiles de las asociaciones locales \#FridaysForFuture y los de los jóvenes activistas que han asumido su liderazgo en España -los estudiantes en Girona Lucas Barrero, Ander Congil y Roger Pallàs- generan una serie de interlocutores, entre los que destacan las organizaciones ecologistas, como Greenpeace, SEO/BirdLife o Ecologistas en Acción. Greenpeace, por ejemplo, ha difundido una carta de apoyo a \#FridaysForFuture, siendo frecuentes las interacciones entre su cuenta @greenpeace_ esp y las de distintas asociaciones locales juveniles.

Por su parte, el movimiento iniciado por Greta Thunberg busca tener cabida en los medios de comunicación, capaces de incidir en la opinión pública según la teoría de la agendasetting (McCombs y Shaw, 1972). En España, sus principales interlocutores son medios de centro-izquierda (El País, Eldiario.es o La Marea) y el área de la Agencia EFE para asuntos medioambientales (EFEVerde). Una muestra es la carta abierta de \#FridaysForFuture España (Clota et al., 2019), publicada en El País y que urge a los representantes políticos a tomar medidas drásticas frente al cambio climático.

Esta interlocución se vislumbra entre medios en su mayoría progresistas y el fenómeno \#FridaysForFuture. Por ejemplo, Eldiario.es compartió en su perfil de Twitter una noticia propia sobre el deseo de los participantes en el movimiento de que el fenómeno tuviera incidencia política (ver Imagen 7). Esta difusión es agradecida públicamente por las propias cuentas de \#FridaysForFuture en España mediante respuestas o retuits. La importancia de estas informaciones radica en su capacidad de establecer la protesta como tema de agenda pública, mostrando su trascendencia social y multimedia.

Con respecto al papel de los partidos políticos en tanto que interlocutores, como se comenta en el apartado anterior la mayor atención a este movimiento procede de las fuerzas de izquierda, sin mención a este asunto a la derecha del tablero político. No obstante, las referencias al fenómeno \#FridaysForFuture son diferentes entre partidos. 
Mientras que el PSOE realiza una especie de declaración institucional en Twitter de apoyo al movimiento (ver Imagen 8), otras formaciones como Izquierda Unida o Equo trascienden del mero apoyo, utilizando el hashtag \#FridaysForFuture para difundir contenido de interés relativo a la emergencia climática (Imagen 9).

eldiario.es 0

Eeldiarioes

Un voto para el planeta: los jóvenes del "Fridays for

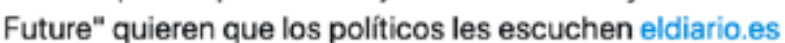
/aragon/planeta... Por @Msalguerom \#FridaysForFuture

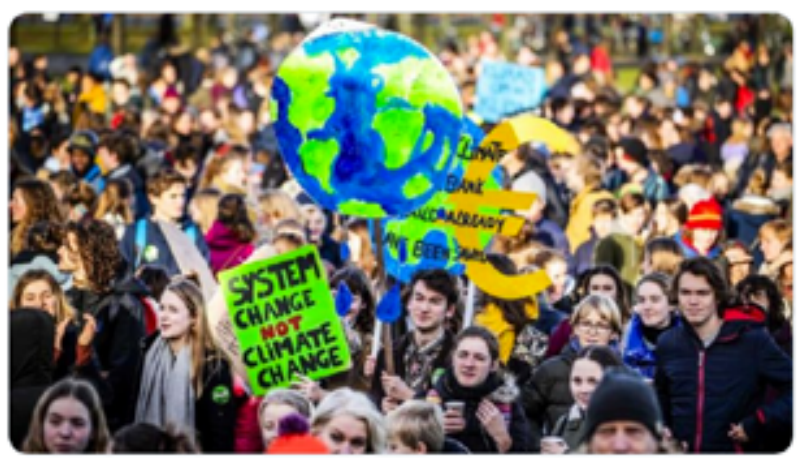

5:50 p. m. - 19 abr. 2019 - TweetDeck

20 Retweets 26 Me gusta

Imagen 7. Tuit de Eldiario.es con información acerca de \#FridaysForFuture.

Fuente: Twitter (@eldiarioes).

\section{PSOE}

PSOE 6

PPSOE

@abalosmeco: \#PSOE se suma a \#FridaysForFuture, movimiento internacional liderado por estudiantes contra el \#CambioClimático. No abordar el reto pone en peligro nuestro modelo de crecimiento. Nos arriesgamos a que España se descuelgue de la economía verde.

\section{\#LaEspañaQueQuieres}

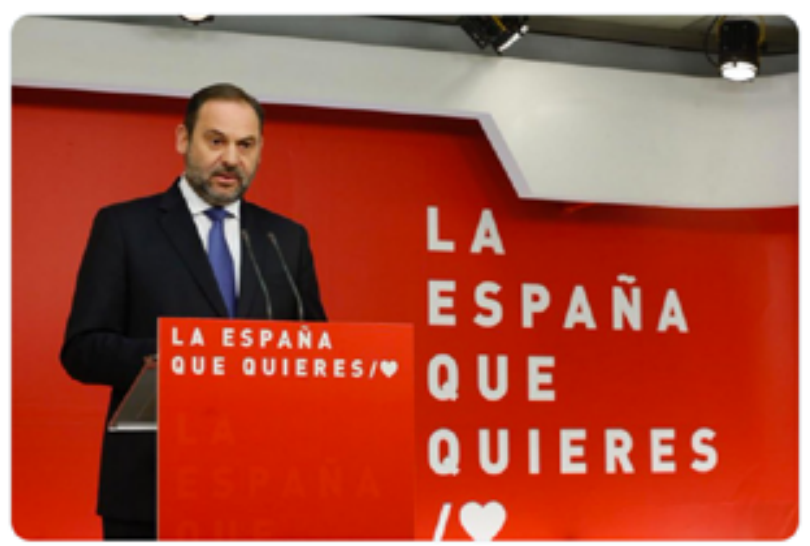

1:20 p. m. - 11 mar. 2019 - Twitter Web Client

102 Retweets 124 Me gusta

Imagen 8. Tuit del PSOE que apoya a \#FridaysForFuture.

Fuente: Twitter (@PSOE).

\subsection{Análisis discursivo}

Para el análisis discursivo se toman 3 casos de mensajes pioneros difundidos por el movimiento \#FridaysForFuture en España, que consideramos que pueden servir de aproximación para conocer algunas de las formas que este proceso de opinión pública tiene de articular su contenido en la Red. No se trata de un estudio sistemático, sino de ejemplos de interés que presentan características discursivas que han sido observadas en otros tuits en torno a este fenómeno.

1. El primero de ellos (Imagen 10) fue publicado por Juventud por El Clima el 20 de abril de 2019. En este mensaje, que constituye la primera referencia a un contenido televisivo en directo, se expone una pregunta escéptica sobre la falta de referencias al cambio climático en el debate electoral de los candidatos a la presidencia del Gobierno para las elecciones del 28 de abril. Esta cuestión se acompaña de un GIF de una persona también en estado

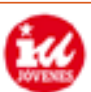

Jóvenes Izquierda Unida $\nabla$

(ㄱovenesIU

Pintar de verde al mismo sistema económico depredador de siempre no soluciona nada.

67 La revolución ecológica es socialmente necesaria y científicamente viable, si echamos a políticos que se deben a grandes empresas.

bit.ly/2V8jPKj

\#FridaysForFuture \#Tulzquierda

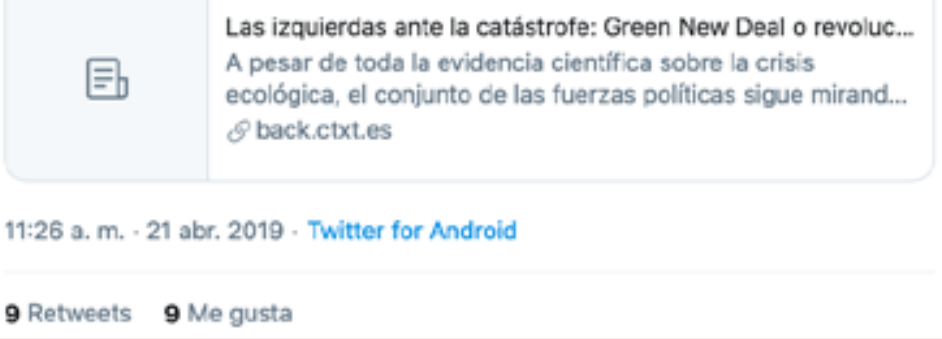

Imagen 9. Tuit de las Juventudes de Izquierda Unida que comparte bajo el hashtag \#FridaysForFuture un artículo sobre la revolución ecológica. | Fuente: Twitter (@JovenesIU). 
incrédulo. La información se distribuye por medio de una pregunta dotada a su vez de signos de exclamación, que marca desde un primer momento y de forma concisa el sentido receloso del mensaje. El estilo es informal, propio de una conversación entre conocidos.

En cuanto a la retórica, se aprecia una cierta ironía en el tuit, que se desarrolla con la estructura lógica de una pregunta, si bien se producen fallos gramaticales, seguramente justificados por la informalidad del estilo. El carácter desenfadado es fácilmente perceptible en el uso de un GIF, un recurso habitual de la comunicación digital entre jóvenes.

2. El segundo de los mensajes (Imagen 11) hace referencia a un tuit difundido por \#FridaysForFutureValéncia. Su contenido realiza un llamamiento para la movilización en las calles contra el cambio climático del 25 de abril de 2019, exponiendo asimismo los motivos para ello. El texto se organiza en tres bloques, marcados por emoticonos, a los que se añade la imagen de la convocatoria. Primero se alude a que los políticos no se toman en serio la crisis climática, para después afirmar que los jóvenes no se quedarán callados, siendo el último punto la llamada a la protesta. Los dos últimos apartados se efectúan entre signos de exclamación.

El sentido del tuit de \#FridaysForFutureValència es claramente reivindicativo, con un estilo conflictivo: "como los políticos no prestan suficiente atención a lo verdaderamente importante (el clima), hemos decidido movilizarnos". Además, estilísticamente los noes van en mayúscula, así como datos claves de la movilización como la fecha y el lugar (toda España). No se aprecian figuras retóricas reseñables.

En cuanto a la estructura, los dos primeros bloques siguen el esquema sujeto, verbo y predicado, paradigmático de las frases enunciativas. El tercero sitúa en primer lugar el complemento circunstancial de tiempo que cita la fecha de la protesta. No obstante, el elemento estructural más significativo es la presencia de un componente causal, a

Juventud Por El Clima - Fridays For Future Espan̆a. (9). JuventudXClima

¿¡Dónde están las referencias y medidas contra el \#CambioClimático Que yo lo vea!? \#L6Ndebatea7

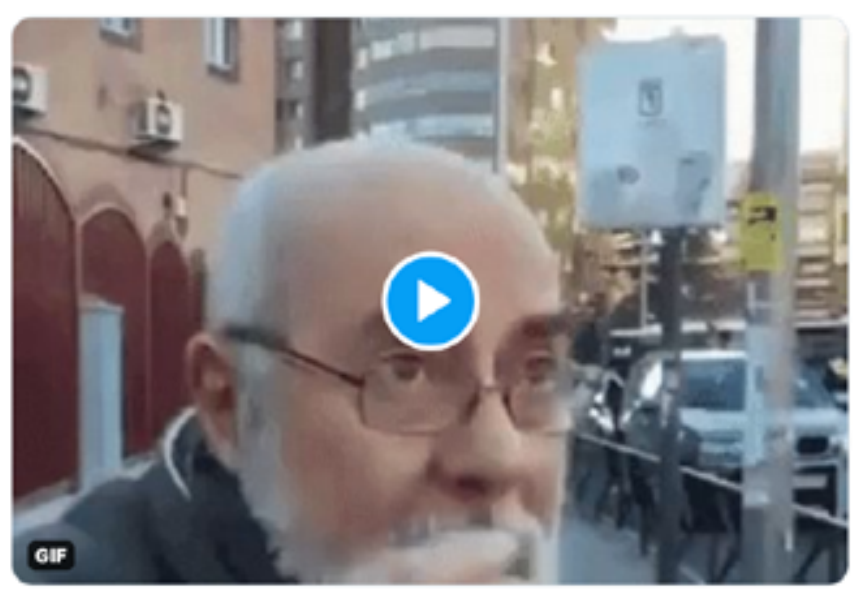

1:11 a, m. 21 abr, 2019 . Twitter for Android

7 Rotwoets 20 Me gusta

Imagen 10. Tuit de interés discursivo de Juventud Por el Clima.

Fuente: Twitter (@JuventudXClima).

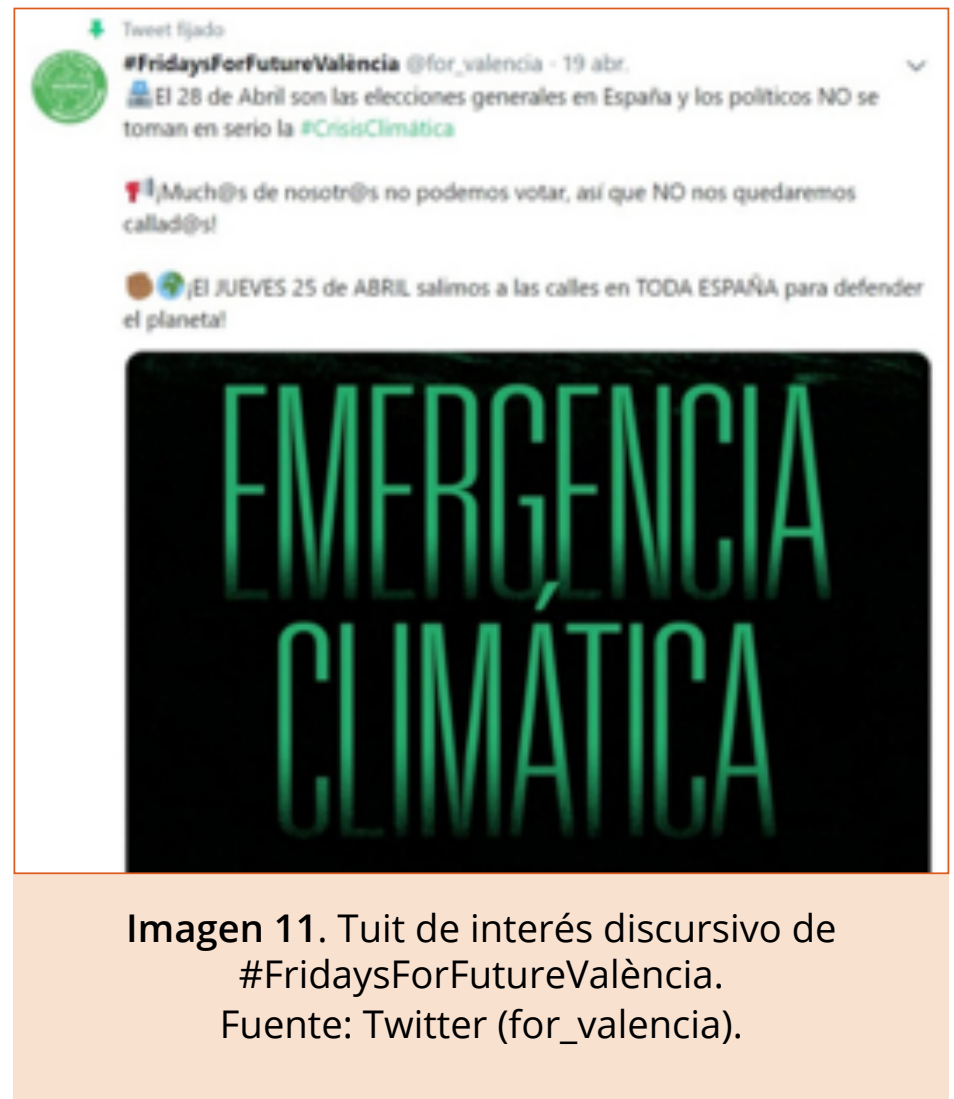


través de la conjunción "así que", que provoca que la segunda parte del tuit funcione como una consecuencia de la anterior, encontrándose perfectamente justificada.

3. El último tuit examinado pertenece a Fridays For Future Barcelona (Imagen 12), el primero del corpus que promueve un cambio de hábitos individuales. La información se distribuye en un párrafo extenso, que aglutina la mayor parte del contenido. Al él se le incorpora una frase final interpelativa y un meme de Yoda -personaje de Star Wars-, otra práctica comunicativa habitual entre la juventud. Los emoticonos en este caso se encuentran menos presentes, pero su dimensión ecologista resulta evidente, al publicar un plato de ensalada y un corazón de color verde.

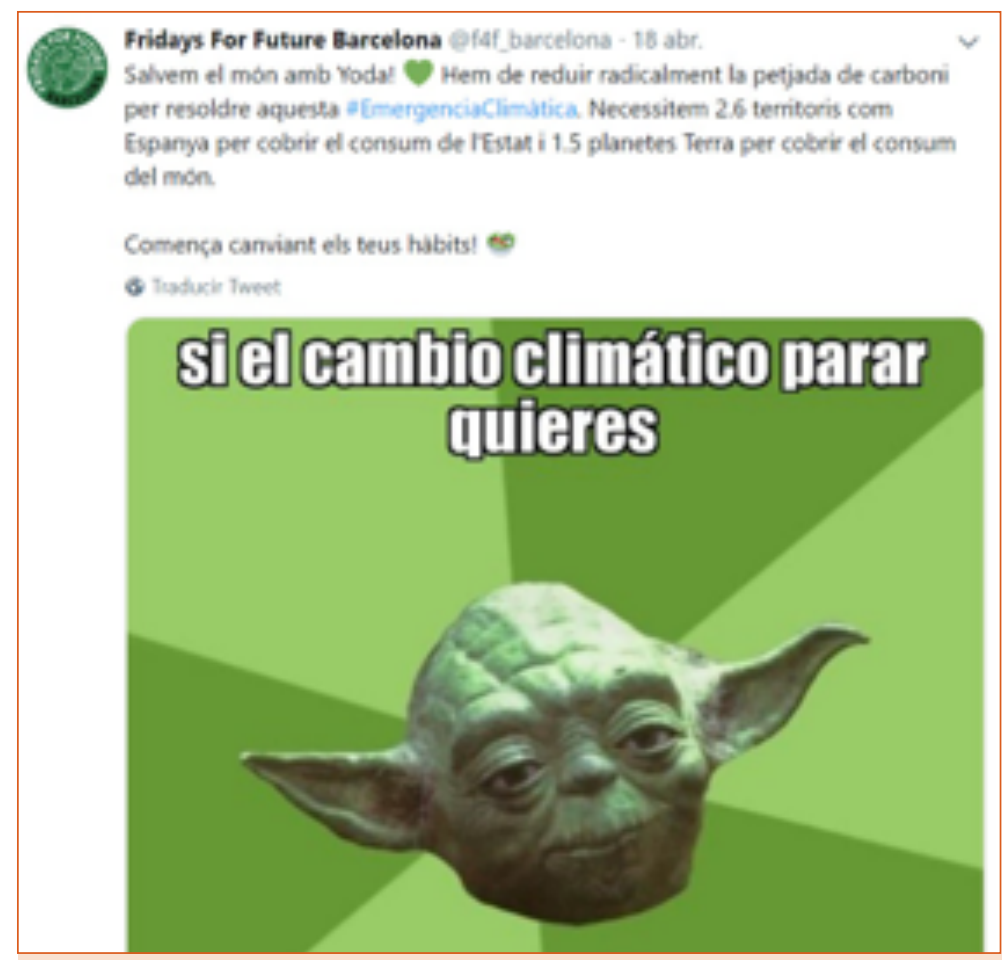

Imagen 12. Tuit de interés discursivo de Fridays For Future Barcelona.

Fuente: Twitter (@f4f_barcelona).
El sentido del mensaje de Fridays For Future Barcelona se halla entre la información y la movilización. Por un lado, se aportan datos de la huella ecológica a nivel español y mundial. Por otro, se insta al cambio de costumbres y a la movilización para reducir este volumen de consumo de recursos, lo que se valora como clave para frenar el cambio climático. El estilo que preside este mensaje es informal, citando a un personaje de la cultura popular como Yoda, pero la presentación de la información es más sobria que en otros tuits estudiados. No hay mayúsculas ni un uso reiterativo de exclamaciones. Lo que sí que se advierte es una mayor dimensión retórica, con la frase "Salvemos el mundo con Yoda", juego de palabras original próximo a la hipérbole, mezclando la exageración con la alusión a un personaje de ciencia ficción.

En lo relativo al esquema sintáctico, el guion es en su mayoría similar: sujeto (ausente), verbo y predicado. Solo difieren la primera y la última frase, formuladas en imperativo para salvar el mundo y pedir el cambio de hábitos entre la ciudadanía. Cabe destacar que el sentido del tuit requiere de la lectura del meme de Yoda, donde con una frase en condicional se vincula el contenido del mensaje con el cambio climático, algo perceptible pero no expresamente referenciado en el resto del mensaje.

En resumen, el análisis discursivo de esta selección de tuits referentes a \#FridaysForFuture nos muestra el desarrollo de un discurso activo, no estático, que asume la participación política de los jóvenes. A pesar de que la responsabilidad se vincula a los políticos, se interpela directamente a la movilización de la juventud, lo que denota una creencia asimilada de que la protesta o la modificación de hábitos (Imagen 12) pueden ayudar a cambiar las cosas. Esta idea coincide con la defendida por el movimiento 15M, que valoraba la participación política ciudadana como herramienta para el cambio (Toret, 2013), construyendo también para ello un discurso reactivo. 
El estilo de los mensajes es además desenfadado, empleando recursos acordes al público objetivo juvenil. La estructura sintáctica suele primar los elementos enfáticos, en consonancia con el sentido reivindicativo y movilizador de los tuits. En cambio, las figuras retóricas apenas se cuelan en este fenómeno, que prefiere mecanismos de comunicación más directos y menos sofisticados, algo motivado por la propia dinámica digital en la que se produce \#FridaysForFuture.

\section{Conclusiones y discusión de resultados}

Teniendo en cuenta la información analizada, esbozamos las siguientes conclusiones para los objetivos de la investigación:

1. \#FridaysForFuture nace ligado a la figura de Greta Thunberg, un individualismo propio de la personalización política digital que se reproduce en la aparición del movimiento en España, concretamente en Girona durante el mes de enero de 2019, pero pronto el fenómeno va a adquirir un carácter más organizacional, gracias a la coordinadora Juventud Por el Clima y las distintas agrupaciones locales vinculadas. Esta circunstancia diferencia a España de otros países europeos como Suecia o Bélgica. La importancia de las asociaciones de proximidad se evidencia en su capacidad de canalizar el movimiento en Twitter. Además, la rápida cobertura de estas protestas por los medios conlleva una predisposición a informar sobre el tema, procedente seguramente de su éxito a nivel mundial.

2. Los perfiles públicos de la coordinadora estatal Juventud Por El Clima y las distintas organizaciones locales son los principales canales de expresión en Twitter del movimiento en España. Los mensajes difundidos trataron desde un primer momento de explicar pedagógicamente la iniciativa, sirviéndose de material audiovisual o datos. A pesar de la fortaleza digital de \#FridaysForFuture, no hay que perder de vista que uno de sus mayores canales de expresión es la acción en la calle, a través de actividades performativas de protesta ante sedes gubernamentales. El objetivo de los tuits suele consistir en concienciar y difundir las movilizaciones, que constituyen en sí mismas una forma de expresión física de la iniciativa.

3. Las cuentas de Twitter de \#FridaysForFuture promueven la interacción con los principales actores en asuntos medioambientales en España, desde ONGs a periodistas y administraciones públicas especializadas en el tema. Una dinámica de interacción frecuente es etiquetar a los perfiles de estas figuras en los mensajes difundidos. Partidos políticos y asociaciones, especialmente Extinction Rebellion, se interrelacionan con este contenido. A todo ello se une la comunicación propiciada por las acciones presenciales, organizadas en esta red social.

4. Los interlocutores principales con los que se relaciona el movimiento \#FridaysForFuture en España son las entidades ecologistas Greenpeace, SEO/BirdLife y Ecologistas en Acción, algunos medios de comunicación progresistas (El País, Eldiario.es y La Marea) y los partidos políticos de centro-izquierda y ecologistas. También destaca el movimiento Extinction Rebellion. Todos ellos interactúan con \#FridaysForFuture, singularmente mediante la coordinadora estatal y las asociaciones locales, y en menor medida con jóvenes activistas.

5. El discurso de los mensajes de \#FridaysForFuture analizados tiene un sentido movilizador y reivindicativo, con un estilo informal, que utiliza potencialidades de Twitter habituales entre el público juvenil. La estructura sintáctica sigue parámetros 
enfáticos, subrayando el carácter de emergencia del cambio climático, en aras de conseguir la participación del público en las protestas. Los emoticonos y las mayúsculas son frecuentes para la consecución de estos objetivos.

Los anteriores resultados posibilitan la respuesta a las preguntas de investigación formuladas por este trabajo. En lo referente a la primera cuestión, las personalidades que articulan \#FridaysForFuture durante sus orígenes en España son Lucas Barrero, Ander Congil y Roger Pallàs, vinculados a esta organización en Girona. Sin embargo, el carácter personalista de este movimiento a nivel global con Greta Thunberg, que entronca con un fenómeno de personalización de la política digital, no tiene correspondencia en el desarrollo del caso español. El peso de estos individuos concretos se diluye frente a la coordinadora estatal y la creación de asociaciones locales, cuyos principales interlocutores son entidades ecologistas.

La segunda pregunta de investigación hacía alusión a las estrategias comunicativas utilizadas. Se detectan tuits sencillos en el mensaje, empleando imágenes y vídeos para poner en valor la necesidad de intervenir contra del cambio climático. Aparecen prácticas de comunicación juvenil, como los memes y GIFs. Resulta reseñable que autores como Hopkel y Hestres (2018) indican que estos usos trascienden el ámbito de la juventud, puesto que los activistas y las organizaciones sobre cambio climático comunican de forma similar en Twitter.

Con respecto a la tercera y última pregunta, referente a los interlocutores de \#FridaysForFuture en España, las cuentas de Twitter vinculadas a este fenómeno interpelan a los principales actores en materia medioambiental, etiquetándolos en sus tuits para que amplíen la viralización del fenómeno, hecho que queda demostrado. No solo se trata de entidades ecologistas, sino también de medios de comunicación, periodistas e, incluso, la clase política, por lo que es manifiesta la importancia atribuida a estas figuras tradicionales.

La principal limitación de nuestro artículo alude al diseño metodológico. La muestra del análisis cualitativo es pequeña, lo que reduce la validez de los resultados. Estos deben considerarse como ejemplos de interés para ilustrar tendencias observables en la configuración inicial del fenómeno \#FridaysForFuture en España, tratando de proporcionar claves en su interpretación cualitativa.

Como discusión, cabe señalar que la aparición de las protestas climáticas en este país en enero de 2019 se produjo después de que los medios de comunicación informaran a finales de 2018 de la iniciativa internacional de Greta Thunberg. Por ello, es improbable que en España el movimiento beba exclusivamente de los partidarios de Thunberg en Twitter, existiendo un peso de los medios acorde a la agenda-setting (McCombs y Shaw, 1972). La protesta juvenil mundial contra el cambio climático se convirtió en tema de la opinión pública gracias a la acción mediática (Kitanova, 2019).

Lo anterior significa poner en duda que \#FridaysForFuture sea un proceso de opinión pública netamente generado en la Red, al menos en España. En cualquier caso, los métodos pueden influir en la delimitación de los conceptos, lo que implica valorar que la formación de opiniones no tiene lugar en el vacío social, sino que se realiza a partir de una posición social determinada (Mañas Ramírez, 2008), moldeada en parte por los medios de comunicación. La huelga iniciada por Greta Thunberg puede interpretarse como el paso que muchos estaban esperando, la chispa que prende la mecha de un descontento con la inacción ante el cambio climático. 
En todo caso, parece claro que \#FridaysForFuture posee elementos de fenómeno de ciberpolítica juvenil, que hace cristalizar nuevas relaciones y procesos sociopolíticos, generando un vínculo social identitario de pertenencia al movimiento gracias a herramientas de Internet como Twitter (Feixa, Fernández-Planells y Figueras, 2016). La participación es un concepto muy poliédrico, pero la Red demuestra que su dimensión va más allá del mero registro en una asociación. Se genera de esta manera un proceso de contrademocracia, siguiendo la denominación de Rosanvallon (2007), es decir, una estigmatización permanente de las autoridades, frente a la acción ciudadana que trata de frenar el cambio climático.

Aunque \#FridaysForFuture sea un fenómeno protagonizado por personas muy jóvenes que cuenta con un importante desarrollo en Twitter, su objetivo es institucional, dado que buscar influir sobre los gobernantes. Sus interlocutores poseen un carácter tradicional, desde las entidades de la sociedad civil y los medios de comunicación a los partidos políticos. El trasfondo se sitúa en la idea de gobierno representativo, que este movimiento trata de orientar hacia postulados ecologistas mediante una ciudadanía concienciada en ese sentido. A ello se suma la acción en las calles, una medida de protesta clásica que se conecta con el deseo de materializar un cambio real sobre un tema complejo (Pérez Nieto y Perales Palacios, 2018).

En definitiva, Twitter ha demostrado su potencialidad para comunicar y difundir las convocatorias del fenómeno \#FridaysForFuture en España. La Red se transforma en una entidad social y política propia (Rosanvallon, 2007), pero conectada aquí claramente con la acción presencial. En este sentido, \#FridaysForFuture puede entenderse como "una crítica postmoderna al proceso de postmodernización" (Offe, 1988: 228), ejecutada bajo parámetros digitales dentro de una oleada de preocupación por cuestiones postmaterialistas que conciernen especialmente a los más jóvenes, como el cambio climático.

\section{Referencias}

Almazán, A. (2013): "Viejas y nuevas formas de estudiar la opinión pública”. En: Garrido Martín, A. y Vinuesa Tejero, L. (eds.): La reina del mundo: reflexiones sobre la historia de la opinión pública. Madrid: TGD, pp. 127-145.

Alonso-Muñoz, L., Marcos-García, S. y Casero-Ripollés, A. (2017): “Political leaders in (inter)action. Twitter as a strategic communication tool in electoral campaigns", en Trípodos, $\mathrm{n}^{\circ}$ 39, pp. 71-90.

Alonso-Muñoz, L. y Casero-Ripollés, A. (2018): "Communication of European populist leaders on Twitter: agenda setting and the 'more is less' effect", en El profesional de la información, vol. 27, n 6, pp. 1193-1202. DOI: 10.3145/epi.2018.nov.03

Álvarez Martín, M. (2013): “Cambio climático e Internet: la comunicación del cambio climático en la globosfera hispanohablante". En: Mancinas-Chávez, R. y FernándezReyes, R. (coords.): Medios de comunicación y cambio climático. Sevilla: Fénix Editora, pp. 317-334.

Anderson, A. A. y Huntington, H. H. (2017): “Social Media, Science, and Attack Discourse: How Twitter Discussions of Climate Change Use Sarcasm and Incivility", en Science Communication, vol. 39, n 5, pp. 598-620. DOl: $10.1177 / 1075547017735113$

Bekafigo, M. A. y McBride, A. (2013): “Who Tweets About Politics? Political Participation of Twitter Users During the 2011 Gubernatorial Elections", en Social Sciences Computer Review, vol. 31, n5, pp. 625-643. 
Bennett, L. W. y Entman, R. M. (eds.) (2001): Mediated Politics. Communication in the Future of Democracy. Cambridge: Cambridge University Press.

Blais, A., Gidengil, E., Nevitte, N. y Nadeau, R. (2004): “Where Does Turnout Decline Come From?", en European Journal of Political Research, vol. 43, n² 2, pp. 221-236.

Bouza, F. (2004): "Desventuras de un concepto claro y distinto, opinión pública". En: VV. AA, (ed.): Reflexiones sociológicas. Libro homenaje a José Castillo Castillo. Madrid: CIS, pp. 768-777.

Broersma, M. y Graham, T. (2013): “Twitter as a news source: How Dutch and British newspapers used tweets in their news coverage, 2007-2011", en Journalism Practice, vol. 7 , n 4, pp. 446-464. DOI: 10.1080/17512786.2013.802481

Campos-Domínguez, E. (2017): “Twitter y la comunicación política”, en El profesional de la información, vol. 26, nº 5, pp. 785-793. DOl: 10.3145/epi.2017.sep.01

Capellán, G. (2008): “Introducción: los ‘momentos' de la opinión pública”. En: Capellán, G. (coord.): Opinión Pública. Historia y Presente. Madrid: Trotta, pp. 9-19.

Chadwick, A. (2017): The hybrid media system. Politics and power. New York: Oxford University Press.

Chavero, P. (2013): “Medios de comunicación y redes sociales en las democracias actuales: ¿complementariedad o sustitución? Una aproximación al caso español". En: Cotarelo, R. (ed.): Ciberpolítica. Las nuevas formas de acción y comunicación políticas. Valencia: Tirant Humanidades, pp. 121-146.

Centro de Investigaciones Sociológicas (2018): Barómetro de mayo 2018. Tabulación por variables de preocupación personal ( $n^{\circ} 3213$ ). Recuperado el 5 de marzo de 2020, de http://www.cis.es/cis/opencm/ES/1_encuestas/estudios/ver.jsp?estudio=14399

Clota, A., Barricarte, G., Rubiera, I. y Barrero, L. (23 de abril de 2019): “Se nos acaba el tiempo y se os han agotado las excusas". El País. Recuperado el 5 de marzo de 2020 de https://elpais.com/sociedad/2019/04/21/actualidad/1555875235_243837.html

Comisión Europea (2019): Standard Eurobarometer 92. Publicopinion in the European Union. Tabulation by main concerns variables. Recuperado el 5 de marzo de 2020, de https:// ec.europa.eu/commfrontoffice/publicopinion/index.cfm/survey/getsurveydetail/ instruments/standard/surveyky/2255

Cotarelo, R. (2010): La política en la era de internet. Valencia: Tirant lo Blanch.

Dewey, J. (2004) [1927]: La opinión pública y sus problemas. Madrid: Editorial Morata.

Enli, G. (2017): "Twitter as arena for the authentic outsider: Exploring the social media campaigns of Trump and Clinton in the 2016 US presidential election", en European Journal of Communication, vol. 32, $\mathrm{n}^{\circ} 1$, pp. 50-61.

Feixa, C., Fernández-Planells, A. y Figueras, M. (2016): “Generation\#. Youth movements in the hiperdigital age", en Revista Latinoamericana de Ciencias Sociales, Niñez y Juventud, vol. 1, n 14, pp. 107-120. DOI: 10.116000/1692715x.1416301115

Fernández-Planells, A., Figueras-Maz, M. y Feixa Pàmpols, C. (2014): “Communication among Young people in the \#spanishrevolution: Uses of online-offline tools to obtain information about the \#acampadabcn", en New Media \& Society, vol. 16, n 8, pp. 1287 1308. DOI: $10.1177 / 1461444814530097$

Fielding, N., Lee, R. y Blank, G. (eds.) (2008): The Handbook of Online Research Methods. Londres: Sage.

Gainous, J. y Wagner, K. M. (2014): Tweeting to power: The social media revolution in 
American politics. Oxford: Oxford University Press.

Gallego, A. (2009): “Where Else Does Turnout Decline Come From? Education, Age, Generation and Period Effects in Three European Countries", en Scandinavian Political Studies, vol. 32, $\mathrm{n}^{\circ}$ 1, pp. 23-44.

Gómez-Diago, G. (2010): “Triangulación metodológica: Paradigma para investigar desde la ciencia de la comunicación", en Razón y palabra, n 72.

Gómez Isassi, J. A. y Treviño Espinosa, F. (2015): “Cambio climático y ecosistemas digitales: Las narrativas transmedia como nuevas prácticas comunicativas". Razón y palabra, n० 91.

Habermas, J. (1994) [1962]: Historia y crítica de la opinión pública. Barcelona: Gustavo Gili.

Hopkel, J. E. y Hestres, L. E. (2018): “Visualizing the Paris Climate Talks on Twitter: Media and Climate Stakeholder Visual Social Media During COP21", en Social Media + Society, vol. 4, n³, pp. 1-15. DOI: 10.1177/2056305118782687

Jones, S. (1998): Doing Internet Research. Critical issues and methods for examining the net. Londres: Sage.

Justel-Vázquez, S., Fernández-Planells, A., Victoria-Mas, M. y Lacasa-Mas, I. (2018): "Twitter e información política en la prensa digital: la red social como fuente de declaraciones en la era Trump", en El profesional de la información, vol. 27, n 5, pp. 984-992. DOI: $10.3145 /$ epi.2018.sep.03

Kitanova, M. (2019): "Youth political participation in the EU: evidence from a crossnational analysis", en Journal of Youth Studies. DOI: 10.1080/13676261.2019.1636951

Kühne, R. W. (2019). “Climate Change: The Science Behind Greta Thunberg and Fridays for Future", en OSF Preprints, 2 de septiembre. DOI: 10.31219/osf.io/2n6kj

Luengo, O. G. (2014): “Twitter vs medios tradicionales. ¿Ha implicado Twitter un espacio ciudadano real de intercambio de información?". En: Cotarelo, R. y Olmeda, J. A. (eds.): La democracia del siglo XXI. Política, medios de comunicación, internet y redes sociales. Madrid: Centro de Estudios Políticos y Constitucionales, pp. 409-427.

Mañas Ramírez, B. (2008): “La medida de la opinión pública. Una mirada sociológica”. En: Capellán, G. (coord.): Opinión Pública. Historia y Presente. Madrid: Trotta, pp. 159-179.

Mañas Ramírez, B. (2013): "Más allá de los sondeos: hacia un estudio discursivo de la opinión pública". En: Garrido, A. y Vinuesa, L. (eds.): La Reina del Mundo: reflexiones sobre la Historia de la Opinión Pública. Madrid: TGD, pp. 147-172.

McAllister, I. (2007): “The personalization of politics". En: Dalton, R. y Klingemann, H. D. (eds.): The Oxford Handbook of Political Behaviour. Oxford: Oxford University Press, pp. 571-588.

Merlino, A. (2012): "Análisis de datos cualitativos: hacia un modelo psicosociológico de análisis del discurso". En: Arroyo Menéndez, M. y Sádaba Rodríguez, I. (coords.): Metodología de la investigación social: técnicas innovadoras y sus aplicaciones. Madrid: Síntesis, pp. 19-48.

Newell, R. y Dale, A. (2015): “Meeting the Climate Change Challenge (MC3): The Role of the Internet in Climate Change Research Dissemination and Knowledge Mobilization", en Environmental Communication, vol. 9, $\mathrm{n}^{\circ}$ 2, pp. 208-227. DOl: 10.1080/17524032.2014.993412

O’Brien, K., Selboe, E. y Hayward, B. M. (2018): “Exploring youth activism on climate 
change: dutiful, disruptive, and dangerous dissent", en Ecology and Society, vol. 23, $\mathrm{n}^{\circ}$ 3: 42. DOI: $10.5751 /$ ES-10287-230342

Ohme, J. (2019): "Mobile but Not Mobilized? Differential Gains from Mobile News Consumption for Citizens' Political Knowledge and Campaign Participation", en Digital Journalism. DOI: 10.1080/21670811.2019.1697625

Oficina de Justificación de la Difusión (2019): Informe OJD de diciembre de 2019. Tabulación por variables de tirada. Recuperado el 14 de febrero de 2020, de https://extranet. introl.es/web_ojd/DatosMensuales_ojd.aspx?codigoclasificacion=1

Offe, C. (1988): Partidos políticos y nuevos movimientos sociales. Madrid: Sistema.

Parmelee, J. H. y Bichard, S. L. (2012): Politics and the Twitter revolution. How tweets influence the relationship between political leaders and the public. Lanham, MD: Lexington Books.

Pérez Nieto, T. y Perales Palacios, F. J. (2018): “El cambio climático visto desde internet: una evaluación de su contenido y mensaje", en Estudios sobre el mensaje periodístico, vol. 24, n², pp. 1507-1524.

Rodríguez-Virgili, J., Jandura, O. y Rebolledo-de-la-Calle, M. (2014): “La personalización de la política en la cobertura mediática: una comparación de las campañas electorales en España y Alemania", en Trípodos, vol. 1, n³4, pp. 61-79.

Rosanvallon, P. (2007): La Contrademocracia. La política en la era de la desconfianza. Buenos Aires: Editorial Manantial.

Rubio Gil, M. A. (2013): "Ciberparticipación política de la juventud: El caso Spanish Revolution". En: Cotarelo, R. (ed.): Ciberpolítica. Las nuevas formas de acción y comunicación políticas. Valencia: Tirant Humanidades, pp. 279-297.

Sádaba Rodríguez, I. (2012): "Introducción a la investigación social online". En: Arroyo Menéndez, M. y Sádaba Rodríguez, I. (coords.): Metodología de la investigación social: técnicas innovadoras y sus aplicaciones. Madrid: Síntesis, pp. 197-216.

Sartori, G. (1998): Homo videns. La sociedad teledirigida. Madrid: Taurus.

Segado-Boj, F., Díaz-Campo, J. y Lloves, B. (2016): “Objetivos y estrategias de los políticos españoles en Twitter", en Index. Comunicación, vol. 6, nº 1, pp. 77-98.

Shah, D. (2019): "Viewpoint: Extinction Rebellion: radical or rational?", en British Journal of General Practice, 69 (684), p. 345. DOI: 10.3399/bjgp19X704357

Shaw, A. (2017): "Encoding and decoding affordances: Stuart Hall and interactive media technologies", en Media, Culture \& Society, vol. 39, n 4, pp. 592-602.

Toret, J. (2013): Tecnopolítica: la potencia de las multitudes conectadas. El sistema red 15M, un nuevo paradigma de la política distribuida. Barcelona: IN3, UOC.

Vaccari, C., Chadwick, A. y O'Loughlin, B. (2015): “Dual screening the political: Media events, social media, and citizen engagement", en Journal of Communication, vol. 65, $n^{\circ}$ 6, pp. 1041-1061. DOI: 10.1111/jcom.12187

Van Dijk, T. A. (1989): La ciencia del texto: un enfoque interdisciplinario. Barcelona: Paidós Comunicación.

Van Dijk, T. A. (ed.) (2000): El discurso como estructura y proceso: introducción multidisciplinaria. Barcelona: Gedisa.

Wahlström, M., Kocyba, P., De Vydt, M. y de Moor, J. (Eds.) (2019): Protest for a future: Composition, mobilization and motives of the participants in Fridays For Future climate protests on 15 March, 2019 in 13 European cities. Recuperado el 19 de febrero de 2020, de https://gup.ub.gu.se/file/207863 